\title{
ASTHMA
}

\section{Systemic activity of inhaled corticosteroid treatment in asthmatic children: corticotrophin releasing hormone test}

\author{
L Pescollderungg, G Radetti, E Gottardi, D G Peroni, A Pietrobelli, A L Boner
}

Thorax 2003;58:227-230

See end of article for authors' affiliations

\section{Correspondence to:}

Dr A L Boner, Department of Pediatrics, University of Verona, Policlinic G B

Rossi, P le L Scuro, 37134

Verona, Italy:

attilio.boner@univr.it

Revised version received 9 November 2002

Accepted for publication 20 November 2002

\begin{abstract}
Background: A study was undertaken to assess the function of the hypothalamic-pituitary-adrenal axis (HPA) in a group of asthmatic children before and after treatment with inhaled corticosteroids.

Methods: Thirty prepubertal patients of mean (SD) age 6.7 (1.8) years were treated with inhaled corticosteroids. All children underwent a corticotrophin releasing hormone (CRH) test with evaluation of serum cortisol and adrenocorticotrophin hormone (ACTH) levels before and after 3 months of treatment. Twenty four hour urine samples were also collected to measure free cortisol (UFC) excretion.

Results: Subjects showed no difference between basal serum cortisol levels (mean change $-18 ; 95 \%$ $\mathrm{Cl}-41$ to $5 ; \mathrm{p}=0.118$ ) and delta (peak minus basal) levels (mean change $-13 ; 95 \% \mathrm{Cl}-38$ to 12 ; $\mathrm{p}=0.308$ ) before and after treatment, whereas the peak cortisol level (mean change $-31 ; 95 \% \mathrm{Cl}-55$ to $-7 ; p=0.013$ ) and area under the curve (AUC) (mean change $-175 ; 95 \% \mathrm{Cl}-288$ to -63 ; $\mathrm{p}=0.003$ ) after $\mathrm{CRH}$ were significantly lower following treatment. Basal, peak and AUC ACTH were significantly lower after treatment $(p<0.05, p=0.004$ and $p=0.003$, respectively), while delta ACTH was similar before and after treatment ((mean change $-12 ; 95 \% \mathrm{Cl}-31$ to $-7 ; p=0.199)$. No significant reduction in 24 hour UFC was observed after the treatment period (before 14.9 (7.1), after 15.0 (11.6); mean change $0.1,95 \% \mathrm{Cl}-5.2$ to $5.4 ; p=0.967)$. No correlation was found between UFC and any of the parameters of cortisol excretion following the CRH test, either before or after treatment. Conclusions: These data suggest that, at the dosage and for the treatment period used, inhaled steroids do not seem to suppress the HPA axis in the majority of patients. The CRH test may be more sensitive than 24 hour UFC and morning plasma cortisol levels in evaluating systemic activity of inhaled corticosteroid treatment.
\end{abstract}

lon nhaled corticosteroids (ICS) are regarded as the first line of anti-inflammatory treatment for asthma ${ }^{1-3}$ because of their lower systemic adverse effects compared with oral corticosteroids. Nonetheless, the possibility of unwanted systemic effects following long term use of ICS is still a concern, especially among pediatricians. ${ }^{4}$ The side effects seem to be mainly dose dependent..$^{5-7}$ Low doses of fluticasone propionate $(200 \mu \mathrm{g} / \mathrm{day})^{8}$ or budesonide $(400 \mu \mathrm{g} / \mathrm{day})^{89}$ are usually considered safe, although adrenal suppression has been reported even at these doses. ${ }^{10}$

The optimal test to detect adrenal suppression is still a matter of debate. ${ }^{41}$ Assessment of adrenal function by measuring morning serum cortisol levels and urinary free cortisol (UFC) excretion provides information on the basal endogenous adrenocortical activity and not on the ability of the axis to react to a stress. Furthermore, UFC is a valuable tool in conditions resulting from high cortisol levels, but it is not useful when hypocorticism is suspected. ${ }^{12}$ This is related to the lack of sensitivity of the method at low cortisol levels ${ }^{13}$ and because low cortisol excretion is often found in healthy individuals. ${ }^{12}$. Despite these limitations, morning basal cortisol concentrations and UFC excretion are frequently used by respiratory physicians to evaluate the adrenal suppressive effect of ICS. ${ }^{14}$ Furthermore, it has been observed that state of the art teststhat is, adrenocorticotrophin hormone (ACTH) stimulation test and measurement of the 24 hour integrated serial plasma cortisol concentration-have been inappropriately used. ${ }^{15}$ It has recently been shown in small number of adult asthmatics that the corticotrophin releasing hormone $(\mathrm{CRH})$ test, which stimulates pituitary ACTH secretion and subsequently cortisol secretion from the adrenal glands, provides a more accurate assessment of the function of the entire hypothalamicpituitary-adrenal (HPA) axis than the ACTH test. ${ }^{16}{ }^{17}$ The CRH test is also a sensitive tool for evaluating the ability of the HPA axis to react to stress. ${ }^{18}$

The aim of this study was to evaluate the systemic effect of ICS treatment, as detected by morning serum cortisol levels, 24 hour UFC excretion, and the CRH test, to compare the relationship between basal and systemic activity of the adrenal glands in asthmatic children.

\section{METHODS \\ Patients:}

Thirty two prepubertal children suffering from frequent episodic or persistent asthma who required maintenance treatment with ICS were studied. ${ }^{19}$ Sixteen received inhaled fluticasone propionate (FP) by a metered dose inhaler (MDI) and spacer (Aereochamber), $100 \mu \mathrm{g}$ twice daily $(50 \mu \mathrm{g}$ per actuation), and 16 received budesonide (BUD), $200 \mu \mathrm{g}$ twice daily by Turbohaler ( $200 \mu \mathrm{g}$ per actuation). Two subjects in the FP group failed to present at the scheduled visits and did not complete the study. Data are therefore presented on 30 patients (14 treated with FP and 16 treated with BUD) of mean (SD) age 6.7 (1.8) years, a height standard deviation score of $0.45(0.77),{ }^{20}$ body mass index (BMI) of SDS -0.1 $(0.98),{ }^{21}$ and body surface area $1.05(0.35)$. The children were supervised in the correct use of the devices according to the manufacturers' recommendations. Each dose was given at 08.00 and 20.00 hours. No child had been treated with oral or nasal corticosteroids in the previous 6 months and none had received inhaled corticosteroids. None of the children suffered from enuresis.

\section{Study design}

The HPA axis was evaluated in all children at baseline and 12 weeks after treatment with ICS. After an overnight fast and 
Table 1 Cortisol and $\mathrm{ACTH}$ response to corticotropin releasing hormone $(\mathrm{CRH})$ stimulation before and after 3 months of treatment

\begin{tabular}{|c|c|c|c|c|c|c|c|}
\hline \multirow[b]{2}{*}{ Variable } & \multicolumn{2}{|l|}{ Before } & \multicolumn{2}{|l|}{ After } & \multicolumn{2}{|c|}{ After - before } & \multirow[b]{2}{*}{$\mathrm{p}$ value* } \\
\hline & Mean & SD & Mean & SD & Mean & $95 \% \mathrm{Cl}$ & \\
\hline \multicolumn{8}{|c|}{ Cortisol (ng/ml) } \\
\hline Basal & 155 & 65 & 137 & 78 & -18 & -41 to 5 & 0.118 \\
\hline Peak & 269 & 57 & 238 & 58 & -31 & -55 to -7 & 0.013 \\
\hline Delta & 114 & 59 & 101 & 53 & -13 & -38 to 12 & 0.308 \\
\hline AUC & 1275 & 303 & 1100 & 327 & -175 & -288 to -63 & 0.003 \\
\hline \multicolumn{8}{|c|}{ ACTH $(p g / m l)$} \\
\hline Basal & 41 & 43 & 27 & 22 & -14 & -27 to -0.4 & 0.045 \\
\hline Peak & 88 & 51 & 62 & 35 & -26 & -43 to -9 & 0.004 \\
\hline Delta & 47 & 44 & 35 & 32 & -12 & -31 to 7 & 0.199 \\
\hline AUC & 298 & 159 & 221 & 93 & -77 & -124 to -29 & 0.003 \\
\hline UFC & 14.9 & 7.1 & 15.0 & 11.6 & 0.1 & -5.2 to 5.4 & 0.967 \\
\hline
\end{tabular}

after the first dose of ICS, a CRH test ( $1 \mu \mathrm{g} / \mathrm{kg}$ IV as bolus) was performed at 09.00 hours to assess serum cortisol and ACTH levels (samples drawn at the following times: $-15,0,15,30,45$, 60, 90, 120 minutes). Twenty four hour urine samples were collected at home on the previous day for UFC assessment. All samples were frozen at $-20^{\circ} \mathrm{C}$ until assayed.

Cortisol was assayed with Immulite 2000 cortisol kit (DPC, Los Angeles, CA, USA) which has a sensitivity of $0.02 \mu \mathrm{g} / \mathrm{ml}$ with an intra-assay coefficient of variation (CV) of $7.2 \%$. ACTH was assayed with the Immulite 2000 ACTH kit (DPC, Los Angeles, CA, USA) which has a sensitivity of $5 \mathrm{pg} / \mathrm{ml}$ with intra- and inter-assay CVs of $6.7 \%$ and $8.2 \%$, respectively. UFC excretion was measured with Immunotech cortisol kit (Marseille, France) which has a sensitivity of $0.36 \mu \mathrm{g} / \mathrm{ml}$ with intraand inter-assay CVs of $3.5 \%$ and $7.5 \%$, respectively.

\section{Statistical analysis}

The aim of this study was to evaluate the behaviour of the basal and reserve activity of the HPA axis after treatment with ICS and not to compare the effect of different corticosteroids. We therefore evaluated all the patients together to study the relationship between basal morning serum cortisol levels, the response to the CRH test, and 24 hour UFC excretion. A sample size of 32 patients was planned to ensure a power of at least $75 \%$ for detecting a difference after treatment of more than half the standard deviation at the usual 5\% level of significance. For each difference a two sided paired $t$ test was applied and the mean change from baseline together with the 95\% confidence interval (95\% CI) was determined. ${ }^{21}$ Correlations were evaluated by linear regression and the area under the curve (AUC) during the CRH test was calculated according to the trapezoidal rule. A p value of $<0.05$ was considered statistically significant. Data were reported as mean values and standard deviations (SD). All statistical calculations were performed using SAS statistical software (SAS, Cary, NC, USA) for personal computers.

The study was approved by the medical ethics committee of our hospital and parents gave written and verbal informed consent for their children.

\section{RESULTS}

No significant change in basal serum cortisol levels (mean change $-18 ; 95 \% \mathrm{CI}-41$ to $5 ; \mathrm{p}=0.118$ ) or delta (peak minus basal) levels (mean change $-13 ; 95 \%$ CI -38 to $12 ; p=0.308$ ) was seen after treatment, but a significant reduction in the peak cortisol level(mean change -31 ; $95 \%$ CI -55 to -7 ; $\mathrm{p}=0.013$ ) and AUC (mean change $-175 ; 95 \%$ CI -288 to -63 ; $\mathrm{p}=0.003$; table 1 ) was seen after the CRH test.

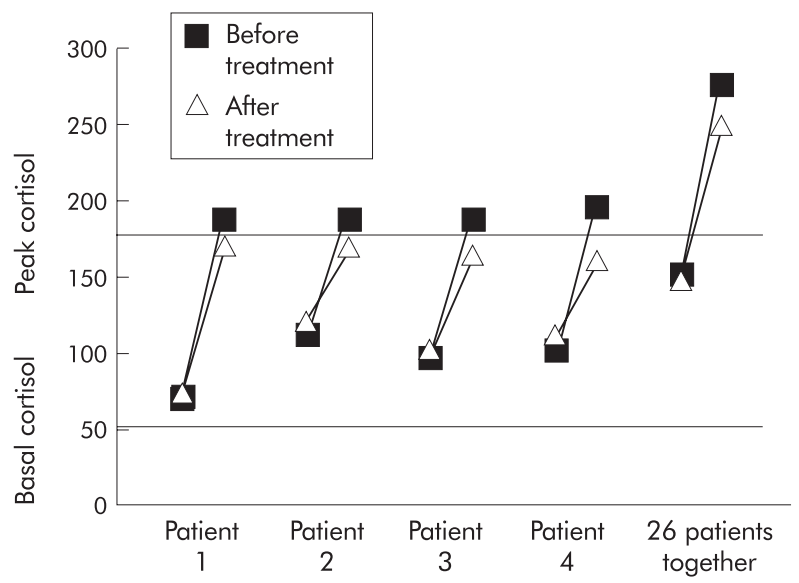

Figure 1 Basal and peak cortisol response to corticotrophin releasing hormone $(\mathrm{CRH})$ before and after treatment with inhaled corticosteroids.

After the 12 week treatment period four patients, two treated with FP and two with BUD, who had a normal response before treatment had an abnormally low peak serum cortisol level ( 168 and $170 \mathrm{ng} / \mathrm{ml}$ in the patients treated with FP, 165 and $161 \mathrm{ng} / \mathrm{ml}$ in the patients treated with BUD, normal value $>180 \mathrm{ng} / \mathrm{ml}$; fig $\mathrm{l}$ ). In these four children, however, the basal serum cortisol level was normal ( 68 and $120 \mathrm{ng} / \mathrm{ml}$ in FP treated patients, 97.8 and $113 \mathrm{ng} / \mathrm{ml}$ in BUD treated patients, normal value $>50 \mathrm{ng} / \mathrm{ml}$ ).

Basal (mean change $-14,95 \% \mathrm{CI}-27$ to $-0.4, \mathrm{p}=0.045$ ), peak (mean change $-26,95 \% \mathrm{CI}-43$ to $-9, \mathrm{p}=0.004$ ), and AUC (mean change $-77,95 \% \mathrm{CI}-124$ to $-29, \mathrm{p}=0.003$ ) ACTH levels were significantly lower after treatment, while delta ACTH was similar before and after treatment (mean change -12 , $95 \% \mathrm{CI}-31$ to $7, \mathrm{p}=0.199$; table 1 ). In three of the four patients with a subnormal peak cortisol response after ICS treatment, the peak ACTH levels were reduced even if they were within the range of our study population, whereas in one patient the ACTH levels showed no change after treatment.

No significant reduction was observed in 24 hour UFC excretion ( $\mu \mathrm{g} / 24$ hours) after treatment (14.9 (7.1) $v 15.0$ (11.6), normal range $2-27 \mu \mathrm{g} / 24$ hours; mean change 0.1 , $95 \%$ CI -5.2 to $5.4, p=0.967$; table 1 ). In three of the four patients with a subnormal peak cortisol response there was also a reduction in 24 hour UFC excretion which was, however, within the observed range of our study population. Nonetheless, one patient showed no changes after treatment. 
No correlation was found between UFC and any of the parameters of cortisol excretion following the CRH test, either before or after treatment with ICS.

\section{DISCUSSION}

Assessment of HPA axis function appears to be the most sensitive and easily measured parameter of the potential systemic side effects of ICS treatment. ${ }^{23}$ The clinical significance of slight alterations in the HPA axis is uncertain and, in most patients, the presence of suppressed endogenous cortisol is not clinically relevant in itself. However, it can be used as a marker of systemic activity of steroid treatment ${ }^{24}$ as well as a surrogate marker for potential adverse effects in other tissues. ${ }^{7}$ Based on this, the aim of our study was to assess the function of the HPA axis in a group of corticosteroid naïve asthmatic children before and after treatment with ICS.

Two broad types of tests can be used to detect HPA axis function-namely, measurement of basal adrenocortical activity and the dynamic stimulation test to evaluate adrenocortical reserve. In our study the dynamic evaluation of the HPA axis seems to be more sensitive than basal serum cortisol levels and 24 hour UFC excretion in detecting the systemic effect of corticosteroid treatment. Following the CRH test, four of our children (two treated with FP and two with BUD) had an inadequate response which could not have been predicted by normal morning serum cortisol levels (fig l). The CRH test enables suppression of pituitary ACTH secretion to be distinguished from the more direct action on the adrenal response to ACTH. The CRH test stimulates pituitary ACTH secretion and this, in turn, produces a cortisol signal from the adrenal gland. It has been suggested that this physiological stimulation by including pituitary assessment may be more sensitive at detecting systemic steroid induced effects than basal adrenal testing alone, particularly with low dose ICS treatment. ${ }^{17}$

In our study the lower peak ACTH secretion after treatment suggests that the suppression is mainly at the HPA level. Even though there were trends for both cortisol and ACTH reduction after treatment in all the parameters measured (table 1), only some of these changes reached statistical significance, reflecting the variability of the measurements and the changes over time, in addition to the effects of ICS treatment. More patients would improve the statistical power of the study, but it is difficult to find oral and inhaled corticosteroid naïve asthmatic children and, furthermore, no previous study with the CRH test has been performed in asthmatic children. Studies done in adults have involved only a few patients. ${ }^{16}{ }^{17}$ Although a type 2 error cannot be excluded, the trend in our results suggests that the CRH test provides more information than other evaluations of the HPA axis. Due to inter- and intra-subject variations, single morning serum cortisol levels have a low sensitivity for detecting adrenal insufficiency and should not be used to compare the effects of different ICS on the HPA axis. ${ }^{11}{ }^{15}$ This is further supported by the fact that basal serum cortisol levels do not adequately predict the response to other dynamic stimulations of the HPA axis with ACTH or with insulin induced hypoglycaemia. ${ }^{25}$

The 24 hour UFC excretion did not change after treatment in our study population. This was also the case in the four children with a reduced peak cortisol response; although it was reduced, 24 hour UFC excretion remained within the normal range. Furthermore, we did not find any correlation between 24 hour UFC excretion and adrenal dynamic response. This was in agreement with the findings in a study in adults. ${ }^{26}$ On the other hand, other studies in adult patients have shown that suppression of 24 hour UFC excretion by ICS correlates with blunting of the stimulated cortisol response to $\mathrm{CRH}^{6}$ or to a physiological low dose of ACTH. ${ }^{27}$ These different results can be explained either by inter-individual sensitivity to the systemic effect or by different doses of ICS and their dose-response curve for adrenal suppression. ${ }^{24}$ Furthermore, Fink and colleagues measured UFC in 13 adult subjects after ICS administration (FP or BUD) and concluded that UFC estimation may be an unreliable surrogate marker of adrenal suppression. ${ }^{13}$

Some patients are particularly sensitive to the systemic effects of ICS, which can be occasionally clinically relevant. ${ }^{28}{ }^{29}$ In our patients there was no clinical evidence of adrenal suppression; however, the CRH test proved to be particularly sensitive to detecting the systemic activity of ICS, especially with respect to the ACTH response. The CRH test is expensive but it is not associated with potential side effects observed with other dynamic tests, such as metyrapone and insulin-induced hypoglycaemia. Metyrapone induced dizziness and nausea, as well as hypoglycaemia, and cannot be used in paediatric studies. ${ }^{30}$ The ACTH test might be an alternative, but it only gives an indirect evaluation of the HPA axis and it has already been shown in adult patients to be less accurate than the CRH test. $^{1617}$ Furthermore, both the standard $(250 \mu \mathrm{g})$ and low dose ( $1 \mu \mathrm{g})$ ACTH tests lack the sensitivity and specificity to diagnose ACTH deficiency compared with the metyrapone test in adults. ${ }^{31}{ }^{32}$ Moreover, the ACTH test is contraindicated in allergic and asthmatic subjects because of occasional reports of severe anaphylaxis. ${ }^{17}$

In conclusion, our results suggest that a thorough evaluation of adrenal function cannot be obtained simply by measuring basal serum cortisol concentrations and/or 24 hour UFC excretion. In studies evaluating the systemic effects of ICS, dynamic evaluation of the HPA axis is more appropriate and CRH should provide an alternative research tool in asthmatic children.

\section{ACKNOWLEDGEMENTS}

The authors thank Dr Stella Lucia Volpe (University of Massachusetts, Amherst, MA, USA), Dr Moonseong Heo (Cornell University, White Plains, NY, USA) and Dr Giovanni Visonà for their insightful comments.

\section{Authors' affiliations}

L Pescollderungg, G Radetti, E Gottardi, Department of Pediatrics, Regional Hospital of Bolzano, Italy

D G Peroni, A Pietrobelli, A L Boner, Pediatric Department, University of Verona, Istituto Pio XII Misurina, Italy

\section{REFERENCES}

1 British Thoracic Society. Guidelines for management of asthma: a summary. BMU 1993;306:776-82.

2 National Heart, Lung and Blood Institute. National Asthma Education and Prevention Program. Expert Panel Report 2: Guidelines for the diagnosis and management of asthma. Publication No 97-4051. Bethesda, MD: National Heart, Lung and Blood Institute, National Institute of Health (NIH), 1997.

3 American Academy of Allergy, Asthma and Immunology. Pediatric asthma: promoting best practice. Guides for managing asthma in children. Milwaukee, WI: American Academy of Allergy, Asthma and Immunology, 1999: 66-8.

4 Bazzy-Assad A. Safety of inhaled corticosteroids in children with asthma. Curr Opin Pediatr 2001;13:523-7.

5 Wilson AM, Sims EJ, Lipworth BJ. Dose response with fluticasone propionate on adrenocortical activity and recovery of basal and stimulated responses after stopping treatment. Clin Endocrinol 1999:50:329-35.

6 Broide J, Soferman R, Kivity S, et al. Low-dose adrenocorticotropin test reveals impaired adrenal function in patients taking inhaled corticosteroids. J Clin Endocrinol Metab 1995;80:1243-6.

7 Lipworth BJ. Systemic adverse effects of inhaled corticosteroid therapy: a systemic review and meta-analysis. Arch Intern Med 1999;159:941-55.

8 Lipworth BJ, Clark DJ, McFarlane M. Adrenocortical activity with repeated twice daily dosing of fluticasone propionate and budesonide given via a large volume spacer to asthmatic school children. Thorax 1997:52:686-9.

9 Volovitz B, Amir J, Malik H, et al. Growth and pituitary-adrenal function in children with severe asthma treated with inhaled budesonide. N Engl J Med 1993;329:1703-8.

10 Kannisto S, Korppi M, Remes K, et al. Adrenal suppression, evaluated by a low dose adrenocorticotropin test, and growth in asthmatic children treated with inhaled steroids. J Clin Endocrinol Metab 2000;85:652-7. 
11 Boner AL. Effects of intranasal corticosteriods on the hypothalamic-pituitary-adrenal axis in children. J Allergy Clin Immunol 2001;108(Suppl 1):S32-9

12 Orth DN, Kovacs WJ. The adrenal cortex. In: Wilson JD, Foster DW, Kronemberg HM, Larsen PR, eds. Williams' textbook of endocrinology. Philadelphia: W B Saunders, 1998: 517-664.

13 Fink RS, Pierre LN, Daley-Yates PT, et al. Hypothalamic-pituitary-adrenal axis function after inhaled corticosteroids: unreliability of urinary free cortisol estimation. J Clin Endocrinol Metab 2002;87:4541-6.

14 Chrousos GP, Harris AG. Hypothalamic-pituitary-adrenal axis suppression and inhaled corticosteriod therapy. General principle. Neuroimmunomodulation 1998;5:277-87.

15 Chrousos GP, Harris AG. Hypothalamic-pituitary-adrenal axis suppression and inhaled corticosteriod therapy. Review of the literature. Neuroimmunomodulation 1998:5:288-308.

16 Iwasaki T, Tamura G, Sano K, et al. Comparison of CRH test and ACTH test in patients with bronchial asthma. Arerugi 1999;48:632-8.

17 Clark DJ, Lipworth BJ. Evaluation of corticotropin releasing factor stimulation and basal markers of hypothalamic-pituitary-adrenal axis suppression in asthmatic patients. Chest 1997;112:1248-52.

18 Honour JW. Hypothalamic-pituitary-adrenal-axis. Respir Med 1994;88(Suppl A):9-15.

19 Warner JO, Naspitz CK, Cropp GJ. Third international pediatric consensus statement on the management of childhood asthma. Pediatr Pulmonol 1998:25:1-17.

20 Tanner JM, Whitehouse RH, Takaishi M. Standards from birth to maturity for height, weight, height velocity and weight velocity: British children. Arch Dis Child 1966;41:613-35.

21 Rolland-Cachera MF, Cole TJ, Sempé M, et al. Body mass index variations: centile from birth to 87 years. Eur J Clin Nutr 1991;45:13-21.
22 Dupont WD Plummer WD. Power and sample size calculation: a review and computer program. Controlled Clin Trials 1990;11:1 16-28.

23 O'Byrne P, Pedersen S. Measuring efficacy and safety of different inhaled corticosteroids preparations. J Allergy Clin Immunol 1998; 102:879-86.

24 Lipworth BJ. Adrenal suppression with inhaled corticosteroids. Ann Allergy Asthma Immunol 2001;87:359-61.

25 Stewart PM, Corrie J, Seckl JR, et al. A rational approach for assessing the hypothalamo-pituitary-adrenal axis. Lancet 1988;1:1208-10.

26 Casale TB, Nelson HS, Stricker We, et al. Suppression of hypothalamic-pituitary-adrenal axis activity with inhaled flunisolide and fluticasone propionate in adult asthma patients. Ann Allergy Asthma Immunol 2001;87:379-85.

27 Wilson AM, Lipworth BJ. Dose-response evaluation of the therapeutic index for inhaled budesonide in patients with mild-to-moderate asthma. Am J Med 2000; 108:269-75.

28 Zimmerman B, Gold M, Wherrett D, et al. Adrenal suppression in two patients with asthma treated with low doses of inhaled fluticasone propionate. J Allergy Clin Immunol 1998;101:425-6.

29 Ringdal N, Lundback $B$, Alton $M$, et al. Comparable effects of inhaled fluticasone propionate and budesonide on the HPA-axis in the adult asthmatic patients. Respir Med 2000;94:482-9.

30 Holt PR, Lowndes DW, Smithies E, et al. The effect of an inhaled steroid on the hypothalamic-pituitary-adrenal axis - which tests should be used? Clin Exp Allergy 1990;20:145-9.

31 Suliman AM, Smith TP, Labib M, et al. The low-dose ACTH test does not provide a useful assessment of the hypothalamic-pituitary-adrenal axis in secondary adrenal insufficiency. Clin Endocrinol 2002;56:533-9.

32 Soule S, Van Zyl Smit C, Parolis G, et al. The low dose ACTH stimulation test is less sensitive than the overnight metyrapone test for the diagnosis of secondary hypoadrenalism. Clin Endocrinol 2000;53:221-7.

\section{LUNG ALERT}

\section{No cure for the common cold}

$\Delta$ Barrett BP, Brown RL, Locken K, et al. Treatment of the common cold with unrefined Echinacea. A randomized, double-blind, placebo-controlled trial. Ann Intern Med 2002;137:939-46

$\mathrm{P}$ evious studies of Echinacea have reported success varying from $10 \%$ to $50 \%$ in the treatment of colds. A few randomised trials have reported only a small effect in preventing colds.

In this randomised, double blind, placebo controlled study the authors report on the effect of 10 days of treatment with dried, encapsulated, whole plant Echinacea starting within 36 hours of onset of symptoms in 142 students reporting common colds (69 Echinacea, 73 placebo). Their primary objective was to measure the severity and duration of reported upper respiratory tract infections. They concluded that there was no statistical difference between the two groups. They do, however, believe this should not be the last word on the use of Echinacea in the treatment of colds because (1) they used whole plant mixture rather than extracts as reported in previous trials, (2) they studied a healthy population of students in whom the clinical effect would be small, and (3) the trial was of modest size and would have missed an effect of $5-10 \%$. Furthermore, they did not confirm infection by serological testing or inflammatory markers and simply based it on reported symptoms. This raises doubt about the exact aetiology of the illness.

This is a well designed study which clearly shows that whole plant Echinacea has no significant clinical effect on the course and severity of the common cold, although it is unlikely that this will end discussion on this subject. 